\title{
Mathematical Model for Predicting Flow Stress in Hot Rolling of Alloy Steel
}

\author{
Atsushi Matsumoto*, Shunsuke Sasaki, Tatsuro Katsumura and Hiroki Ota \\ Steel Research Laboratory, JFE Steel, Handa 475-8611, Japan
}

\begin{abstract}
During the multipass hot processing of alloy steel, restoration processes such as static and dynamic recrystallization and recovery occur. Owing to these phenomena, flow stress characteristics are affected by various deformation conditions, such as temperature and accumulated strain. The objective of this research is to develop a mathematical model for predicting flow stress to represent these effects by simply considering the processing history and restoration. Hot compression experiments were conducted and the results were compared with the predicted results. It was found that the prediction accuracy can be improved by simultaneously considering the effects of accumulated strain and restoration. [doi:10.2320/matertrans.P-M2017841]
\end{abstract}

(Received May 25, 2017; Accepted September 25, 2017; Published November 25, 2017)

Keywords: flow stress prediction model, strain rate, temperature, deformation history, alloy steel

\section{Introduction}

In the multipass hot rolling of steels, an accurate model for the prediction of flow stress characteristics that considers work hardening and the static and dynamic recrystallization and recovery of the microstructure is required to determine the optimum manufacturing conditions. The conventional flow stress equations are expressed in terms of temperature, strain and strain rate ${ }^{1,2)}$. However, flow stress characteristics are affected by the deformation history such as the accumulation of strain and by the addition of alloying elements such as chromium, molybdenum and niobium, which retard recovery and recrystallization. Also, if the interpass time of hot rolling is short, then the static recovery and recrystallization are insufficient to release the accumulated strain. As a result, these equations are not valid under various forming conditions. Therefore, many attempts to develop mathematical models of flow stress behavior have been reported. Andrade et al., Saito et al. and Yamamoto et al. respectively reported the effects of molybdenum, niobium and vanadium on static recovery and recrystallization and on solute strengthening ${ }^{3-5)}$. Senuma et al. and Yoshie et al. discussed the effect of strain accumulation on flow stress based on the dislocation density ${ }^{6,7)}$. However, it is difficult to discuss the effects of work hardening and recovery of the microstructure using dislocation theory because it is hard to measure the dislocation density directly. Furthermore, while flow stress equations can be expressed as a function of equivalent strain, equivalent strain is not an internal variable of the material properties but a deformation quantity. As a consequence, a logical contradiction occurs from the viewpoint of metallurgy. To overcome these problems, Yoshino and Shirakashi ${ }^{8-10)}$ proposed a mathematical model for predicting flow stress that included a function of stored energy during the deformation process. In this model, flow stress can be uniquely determined from the stored energy, and the stored energy takes into account the effects of the strain rate and recovery as the accumulation and release of energy, respectively, on flow stress. Furthermore, according to a previous report ${ }^{11)}$, a small percentage of the stored energy in a material is preserved in the form of dislocations. From this

*Corresponding author, E-mail: at-matsumoto@jfe-steel.co.jp viewpoint, restored energy can connect plastic deformation and metallurgical phenomena. In addition, this model can be applied to forming processes with various deformation histories, and difficult experiments or measurements are not required to construct the model and obtain the material parameters. In terms of metallurgy, in this model, the effect of the phase transformation during the process is reflected, but the effect of the addition of alloying elements to the steel on the inhibition of recovery is not known.

In this study, we developed a mathematical model of flow stress based on Yoshino's model for the hot processing of alloy steel and clarified the effect of added elements on prediction accuracy. To determine the retardation of recovery due to the addition of alloying elements to the steel, we prepared materials with different recovery rates and examined the prediction accuracy of the model for these alloy steels.

\section{Experimental Procedure}

Alloy steels with different contents of $\mathrm{Cr}$, Mo and $\mathrm{Nb}$ were prepared. The chemical composition of each low-alloy steel is shown in Table 1. Specimens with $8 \mathrm{~mm}$ diameter and $12 \mathrm{~mm}$ gage length were machined after casting.

A hot uniaxial compressive test was carried out using a thermomechanical simulator (Thermecmaster Z). The specimens were heated to $1250^{\circ} \mathrm{C}$ at a heating rate of $10^{\circ} \mathrm{C} / \mathrm{s}$ and held for $5 \mathrm{~min}$, cooled at a rate of $5^{\circ} \mathrm{C} / \mathrm{s}$, then deformed at temperatures from 900 to $1100^{\circ} \mathrm{C}$. In this study, two series of experiments were performed. One consisted of a series of single-pass compressive tests, in which the specimens were deformed at strain rates from 1 to $20 \mathrm{sec}^{-1}$ to clarify the effects of the temperature and strain rate on the flow stress curves. The other was a series of two-pass compressive tests,

Table 1 Chemical compositions of steels

\begin{tabular}{ccccccccc}
\hline Steel & $\mathrm{C}$ & $\mathrm{Si}$ & $\mathrm{Mn}$ & $\mathrm{P}$ & $\mathrm{S}$ & $\mathrm{Cr}$ & $\mathrm{Mo}$ & $\mathrm{Nb}$ \\
\hline $\mathrm{A}$ & 0.25 & 0.26 & 0.97 & 0.019 & 0.001 & 0.4 & - & - \\
$\mathrm{B}$ & 0.24 & 0.26 & 1.29 & 0.016 & 0.001 & 0.8 & - & - \\
$\mathrm{C}$ & 0.25 & 0.26 & 0.50 & 0.010 & 0.001 & 1.0 & 0.25 & 0.01 \\
$\mathrm{D}$ & 0.24 & 0.25 & 0.60 & 0.007 & 0.001 & 1.0 & 0.75 & 0.01 \\
\hline
\end{tabular}


in which the specimens were deformed at a strain rate of $10 \mathrm{sec}^{-1}$ with an interruption of 1 to $100 \mathrm{sec}$ between the first and second deformation passes. After the interruption, the specimens were reloaded at the same strain rate and temperature. The strain in the first pass was 0.35 and the total strain was approximately 0.75 . To observe the microstructure under each of the interruption time conditions immediately before the second pass, the grain boundaries were exposed by etching in an aqueous solution of picric acid.

\section{Experimental Results and Development of Flow Stress Model}

\subsection{Flow stress curves obtained from hot compressive tests}

Figure 1 shows the flow stress curves obtained from the two-pass compressive tests for Steels A, B, C and D with interruption times from 1 to $10 \mathrm{sec}$ at a temperature of $900^{\circ} \mathrm{C}$. In addition, the flow stress curves obtained from the single-pass compressive test at a strain rate of $10 \mathrm{sec}^{-1}$ are also shown in Fig. 1. The plots are the results of the two-pass compressive tests, and the broken line is the result of the single-pass compressive test loaded up to a true strain of 0.75 . It was shown that two typical behaviors occur during the two-pass compressive tests. For Steels A and B, at the deformation temperature of $900^{\circ} \mathrm{C}$, the flow stress in the two- pass compressive test with an interruption times of $3 \mathrm{sec}$ corresponded to that in the single-pass compressive test. However, when the interruption time was increased to $5 \mathrm{sec}$ or more, the flow stress in the two-pass compressive test was decreased in the second pass and no longer corresponded to that in the single-pass compressive test. On the other hand, in the case of Steels C and D, even if the interruption time was increased to $10 \mathrm{sec}$, the flow stress in the two-pass compressive test almost corresponded to that in the single-pass compressive test. Figure 2 shows the fractional softening, $X$, plotted against the interruption time for different deformation temperatures. $X$ was calculated from the expression

$$
X=\left(\sigma_{m}-\sigma_{y 2}\right) /\left(\sigma_{m}-\sigma_{y 1}\right),
$$

where $\sigma_{m}$ is the flow stress immediately after first stage of compression and $\sigma_{y 1}$ and $\sigma_{y 2}$ are the yield stresses in the first and second stages of compression, respectively. In this study, these yield stress are defined by a conventional offset method $^{12)}$ and corresponded to $0.2 \%$ proof stress in the first and second stages of compression. From Figs. 2(a) and 2(b), the progress of softening of Steel A was almost the same as that of Steel B at all temperatures. Above an interruption time of $10 \mathrm{sec}$, the value of fractional softening becomes 1.0. From Figs. 2(c) and 2(d), the progress of softening in Steels C and D was slower than that in Steels A and B, and it appeared that Steel D exhibited the slowest softening among these materials. The softening included the effects of static recovery and recrystallization ${ }^{13-15)}$. In Fig. 3, the microstructure of each steel immediately before the second stage of compression at $900^{\circ} \mathrm{C}$ is shown for each interruption time. For fractional softening of under 0.5 , as-deformed coarse grains were mostly observed. In the case of fractional softening from 0.5 to 1.0 , coarse grains and grains refined by static recrystallization coexisted. When the fractional soften-
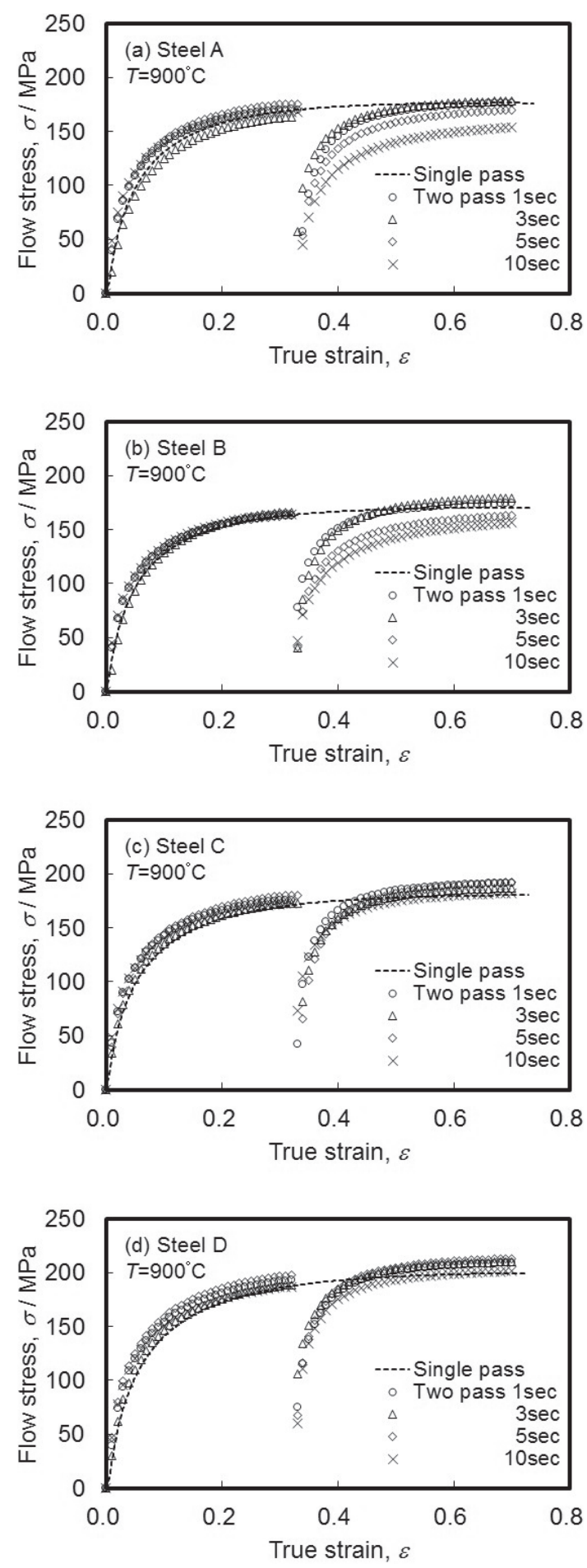

Fig. 1 Flow stress curves of Steels A-D at strain rate of $10 \mathrm{sec}^{-1}$ and deformation temperature of $900^{\circ} \mathrm{C}$.

ing was around 1.0, refined grains accounted for most of the microstructure. In the latter case, it was supposed that the recrystallization behavior had a stronger effect on the softening than static recovery. Therefore, we excluded the experimental results for which the fractional softening was above 1.0 in the construction of the flow stress model considering the recovery effect. 

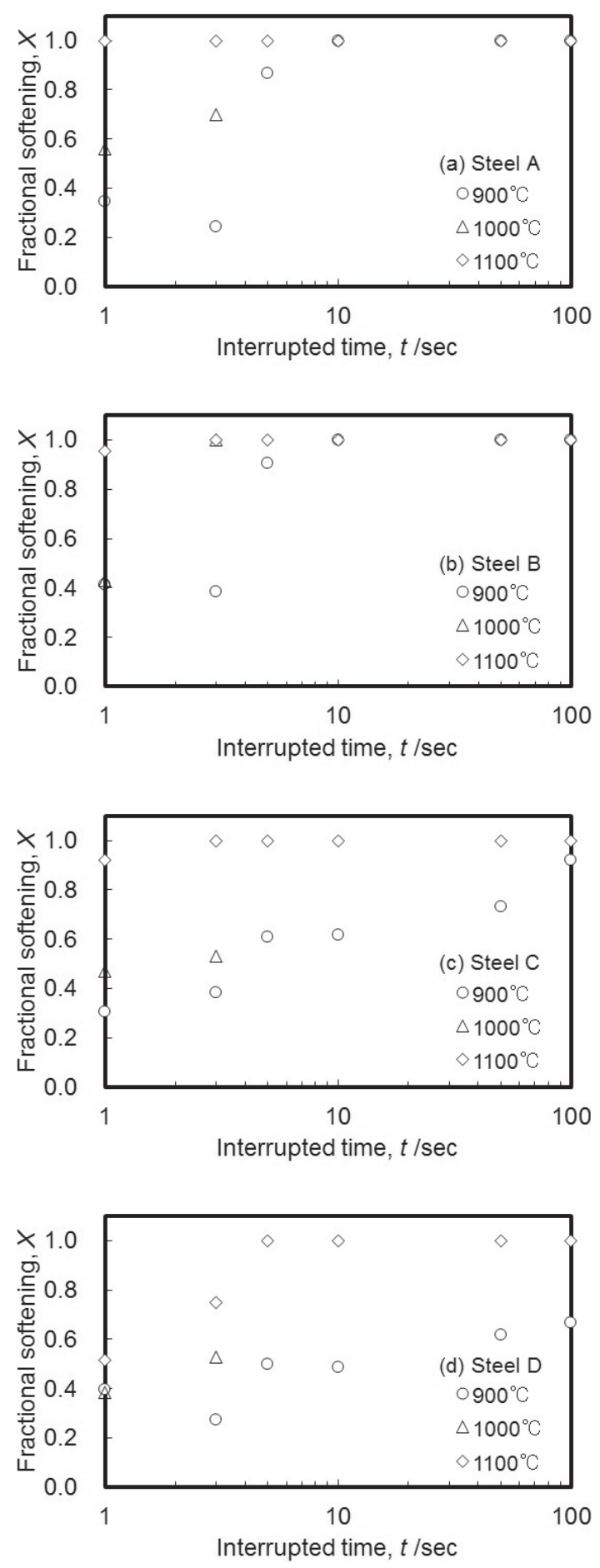

Fig. 2 Relationship between fractional softening and interruption time at deformation temperatures of 900,1000 and $1100^{\circ} \mathrm{C}$.

\subsection{Formulation of flow stress prediction model \\ 3.2.1 Effect of deformation history on flow stress con- sidering recovery}

Without considering the phase transformation, flow stress characteristics have been proposed as functions of the strain rate, temperature and material state, such as the work hardening rate, at the moment of deformation. The details were discussed in previous reports ${ }^{9,10)}$. The material state was estimated from the stored energy $W$ through the deformation history. The function of the flow stress is

$$
\sigma=f(\dot{\varepsilon}, T, W)
$$

where $\dot{\varepsilon}, T$ and $W$ are the strain rate, temperature and stored energy, respectively. The stored energy during plastic deformation including the process of energy release due to recovery is

$$
d W=\sigma d \varepsilon-k W d t,
$$

where $\sigma, \varepsilon, k, W$ and $t$ are the flow stress, strain, recovery coefficient, stored energy and time, respectively. The energy released by the recovery process is given by eq. (4) and shown in Fig. 4. Figure 4 shows that after energy was released during the interruption time, the open plots, which are shifted horizontally from the solid plots, correspond to the solid plots above a strain of 0.3 . This indicates that the stored energy at the start of the second pass was nearly equal to that with a strain of 0.3 in the first pass as a result of this energy release.

$$
d W / d t=-k W \quad k=k_{s} \exp [-C /(T+273.15)],
$$

Here, $k_{s}$ and $C$ are material constants and $T$ is temperature. These material constants were calculated from the results of the two-pass compressive test with an interruption time of up to $3 \mathrm{sec}$, and the logarithm of the recovery coefficient $k$ is plotted against the reciprocal of temperature $T$ in Fig. 5. Also, the material constants $k_{s}$ and $C$ for Steels A-D are shown in Table 2. A higher recovery coefficient indicates a tendency for recovery to occur more easily. From Fig. 5, it is clear that Steel D exhibited the slowest recovery, with the rate of recovery increasing from Steel D to Steel A. It was observed that the $\mathrm{Cr}$ or Mo content affected the recovery coefficient at 900 and $1000^{\circ} \mathrm{C}$ and the $\mathrm{Nb}$ content affected the recovery coefficient up to $1100^{\circ} \mathrm{C}$. Therefore, it was found that the retardation of recovery for materials is reflected in the recovery coefficient $k$ in this prediction model. The stored energy was uniquely determined by a flow stress curve, where the flow stress is called the standard stress $\sigma_{s t}$. Accordingly, the flow stress is also expressed as a function of the standard stress $\sigma_{s t}$, strain rate $\dot{\varepsilon}$ and temperature $T$ as

$$
\sigma=f\left(\sigma_{s t}, \dot{\varepsilon}, T\right)
$$

\subsubsection{Expression for standard stress}

The condition and function type for standard stress $\sigma_{s t}$ is arbitrary ${ }^{16)}$. Therefore, in this study, the standard condition is defined as a deformation temperature of $900^{\circ} \mathrm{C}$ and a strain rate of $10 \mathrm{sec}^{-1}$, and the standard stress equation is expressed by

$$
\sigma_{s t}=A W^{n}+B[2 /\{1+\exp (-\lambda W)\}-1],
$$

where $A, n, B$ and $\lambda$ are material constants and $W$ is stored energy. Figure 6 shows the relationship between the calculated standard stress and stored energy for Steel C. The calculated curve, as shown by the line, corresponds well with the results of the single-pass compressive test, as shown by the plots. The equations of the standard stress for the other steels were also set up in a similar manner. The material constants for Steels A-D are shown in Table 3.

\subsubsection{Effect of strain rate on flow stress}

To consider the effect of the strain rate on the relationship between the standard stress and stored energy, the results of 
(a) Steel A
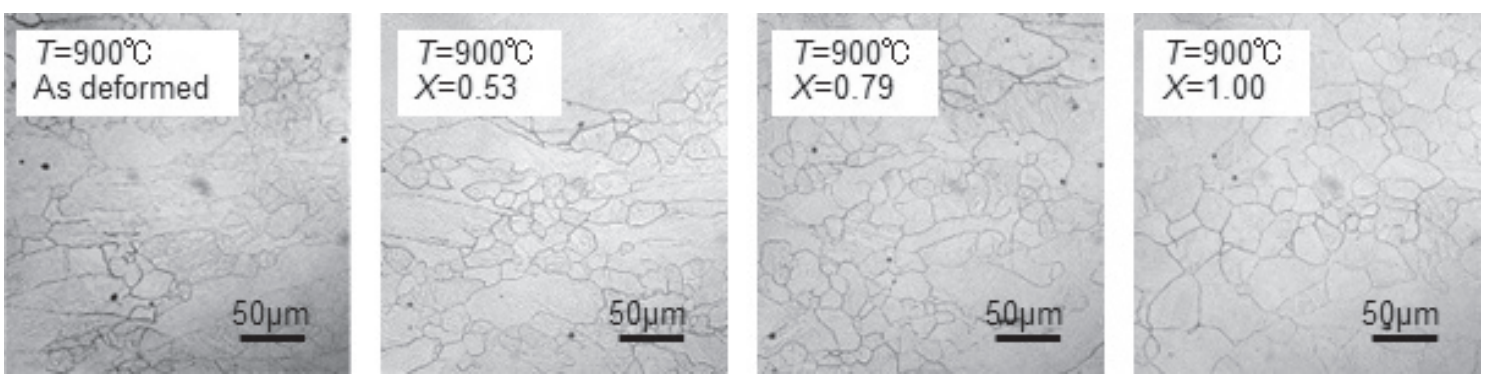

(b) Steel D
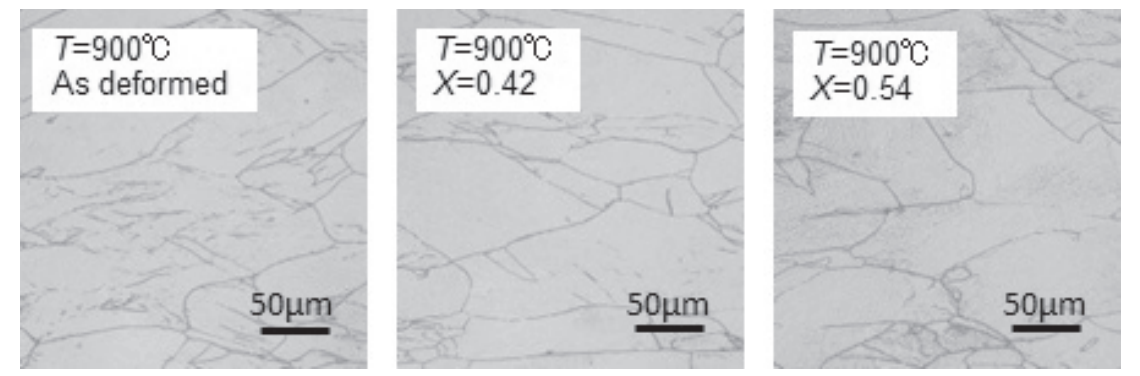

Fig. 3 Microstructure immediately before second stage of compression with deformation temperature of $900^{\circ} \mathrm{C}$ and different amounts of fractional softening.

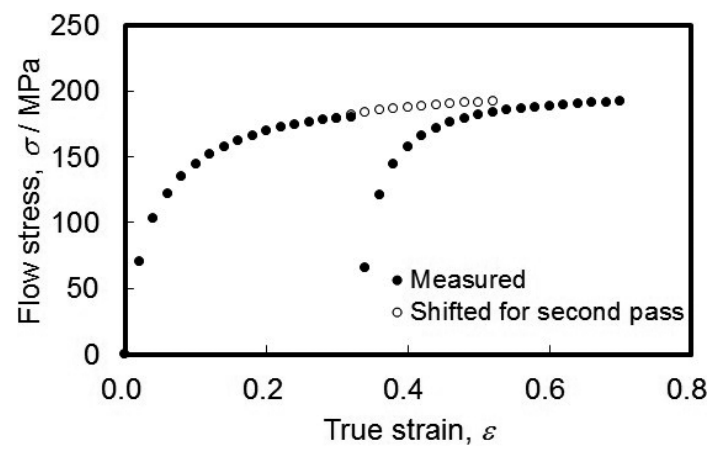

Fig. 4 Effect of deformation history considering effect of energy release on flow stress.

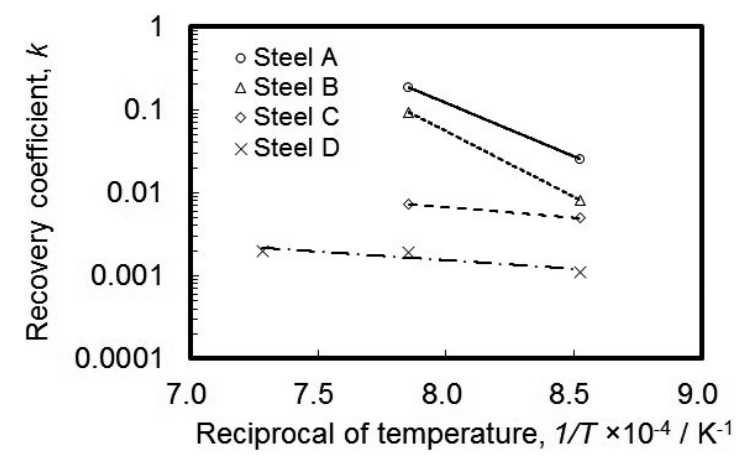

Fig. 5 Effect of temperature on recovery rate of stored energy for each steel.
Table 2 Material constants in recovery coefficient for Steels A-D

\begin{tabular}{ccccc}
\hline Steel & $\mathrm{A}$ & $\mathrm{B}$ & $\mathrm{C}$ & $\mathrm{D}$ \\
\hline$k_{s}$ & $2.438 \times 10^{9}$ & $2.420 \times 10^{11}$ & 0.686 & 0.069 \\
$C$ & -29670 & -36390 & -5796 & -4748 \\
\hline
\end{tabular}

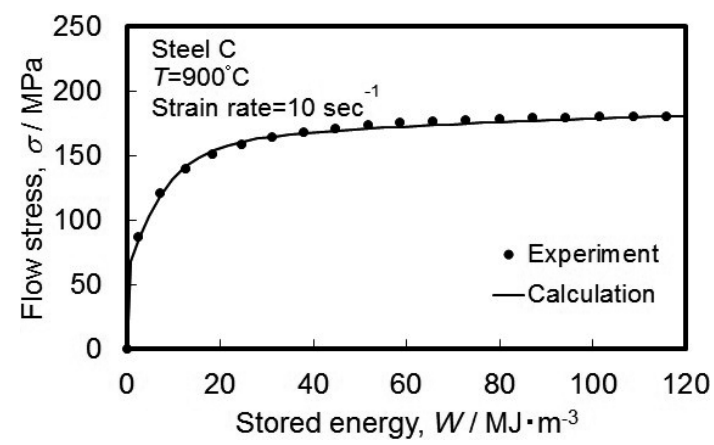

Fig. 6 Relationship between calculated standard stress and stored energy for Steel C.

Table 3 Material constants of standard stress for Steels A-D.

\begin{tabular}{ccccc}
\hline Steel & A & B & C & D \\
\hline$A$ & 42.00 & 41.69 & 64.02 & 69.54 \\
$N$ & 0.1884 & 0.1692 & 0.1129 & 0.1317 \\
$B$ & 81.03 & 82.61 & 71.03 & 70.60 \\
$\lambda$ & -0.3083 & -0.2936 & -0.1717 & -0.1466 \\
\hline
\end{tabular}


the single-pass compressive test at different strain rates at a deformation temperature of $900^{\circ} \mathrm{C}$ are discussed. Figure 7 shows the stress ratio of the flow stress for different strain ratios with the standard stress against the stored energy calculated by eqs. (3) and (4). In this figure, the stress ratio was almost constant except at a low stored energy. Therefore, the stress ratio $\sigma / \sigma_{s t}$ was expressed in terms of the strain ratio function as follows by assuming a power law:

$$
\sigma / \sigma_{s t}=\left(\dot{\varepsilon} / \dot{\varepsilon}_{s t}\right)^{m}=(\dot{\varepsilon} / 10)^{m},
$$

where $\sigma, \sigma_{s t}, \dot{\varepsilon}, \dot{\varepsilon}_{s t}$ and $m$ are the flow stress, standard stress, strain rate, strain rate under the standard condition and material constant, respectively. The values of the material constant $m$ are shown in Table 4.

\subsubsection{Effect of deformation temperature on flow stress}

To consider the effect of the deformation temperature on the relationship between standard stress and stored energy, the results of the single-pass compressive test at a strain rate of $10 \mathrm{sec}^{-1}$ were set as the standard condition. The relationship between the ratio of the flow stress at different deformation temperatures to the standard stress and the stored energy calculated by eqs. (3) and (4) had a similar tendency to that in Fig. 7, which was due to the fact that the stress ratio $\sigma / \sigma_{s t}$ did not depend on the restored energy, and only depended on the deformation temperature. Figure 8 shows the flow stress ratio plotted against the deformation temperature.

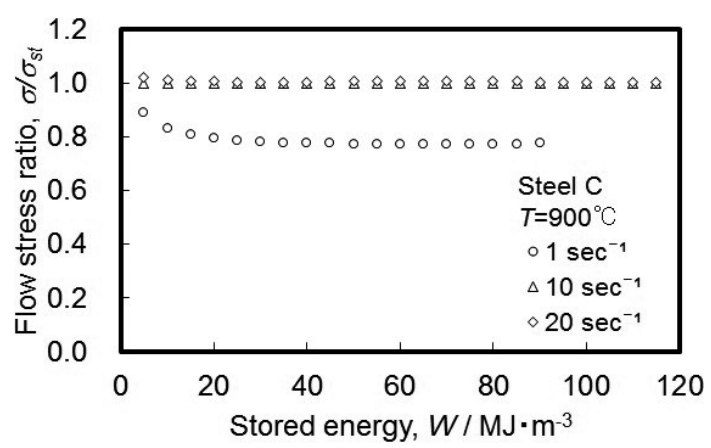

Fig. 7 Effect of strain rate on flow stress ratio.

Table 4 Material constant representing standard stress for Steels A-D.

\begin{tabular}{ccccc}
\hline Steel & A & B & C & D \\
\hline$M$ & 0.1084 & 0.1167 & 0.1008 & 0.0874 \\
\hline
\end{tabular}

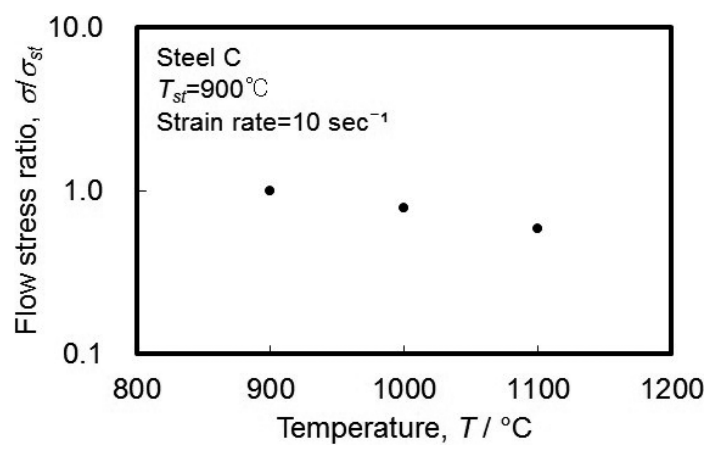

Fig. 8 Effect of deformation temperature on flow stress ratio.
The plots, which show the experimental results, were distributed on a straight line in the single-logarithmic graph. Therefore, the effect of the deformation temperature on the flow stress was expressed as

$$
\sigma / \sigma_{s t}=\exp \left[\alpha\left(T-T_{s t}\right)\right]=\exp [\alpha(T-900)],
$$

where $\alpha, T$ and $T_{s t}$ are the material constant, the temperature and the temperature under the standard condition, respectively. The material constant $\alpha$ for each steel is shown in Table 5 .

Thus, we defined the prediction model for the flow stress with the stored energy $W$ function by combining eqs. (5) to (8) as follows:

$$
\sigma=\sigma_{s t}(W) \cdot(\dot{\varepsilon} / 10)^{m} \exp [\alpha(T-900)],
$$

\section{Experimental Results and Development of Model}

\subsection{Effect of interruption time on prediction accuracy}

To examine the effects of static recovery and recrystallization on prediction accuracy, we compared the calculated flow stress with the results of the two-pass compressive tests with the interruption time varied from 1 to $10 \mathrm{sec}$. Figure 9 shows the stress-strain curves at a strain rate of $10 \mathrm{sec}^{-1}$ at the deformation temperature of $900^{\circ} \mathrm{C}$ for Steels A and D. The plots are the experimental results, and the continuous and broken lines represent the results of the flow stress calculations and the conventional model based on Inouye's model ${ }^{1)}$, respectively. In these figures, the flow stress calculated by the conventional model was larger than the experimental value during the second stage of compression for both steels. This was because the conventional model does not consider the static recovery during the interruption time. For Steel A in Fig. 9(a), the calculated curves were in good agreement with the experimental results for the interruption times of 1 and $3 \mathrm{sec}$ at the deformation temperature of $900^{\circ} \mathrm{C}$. However, the calculated values were larger than the experimental results for interruption times of $5 \mathrm{sec}$ and above. Considering these findings with the results in Fig. 2(a), it was assumed that when the fractional softening was above 0.79 , the effect of softening by static recrystallization on the prediction accuracy of the flow stress in this model increased. Therefore, it appears that the deviation between the experimental and calculation results was due to recrystallization, which this model does not consider. On the other hand, in the case of Steel D at the deformation temperature of $900^{\circ} \mathrm{C}$, the fractional softening was under 0.6 for interruption times from 1 to $10 \mathrm{sec}$, and from Fig. 9(b), the calculated curves were in good agreement with the experimental results. From these results, it is suggested that this model has high prediction accuracy when the fractional softening is under approximately 0.55 .

Table 5 Material constant for effect of deformation temperature.

\begin{tabular}{ccccc}
\hline Steel & A & B & C & D \\
\hline$\alpha$ & $2.419 \times 10^{-3}$ & $2.409 \times 10^{-3}$ & $2.600 \times 10^{-3}$ & $2.613 \times 10^{-3}$ \\
\hline
\end{tabular}


(a) St e e $1 \mathrm{~A}$
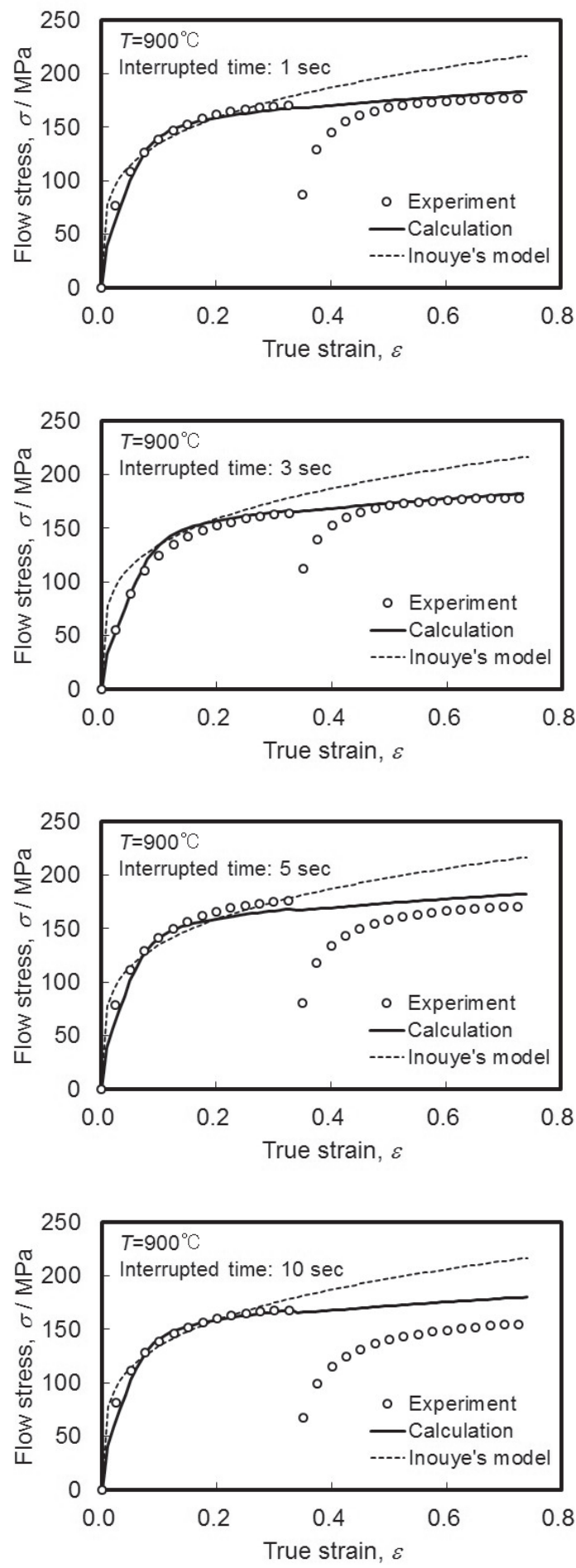

(b) Steel D
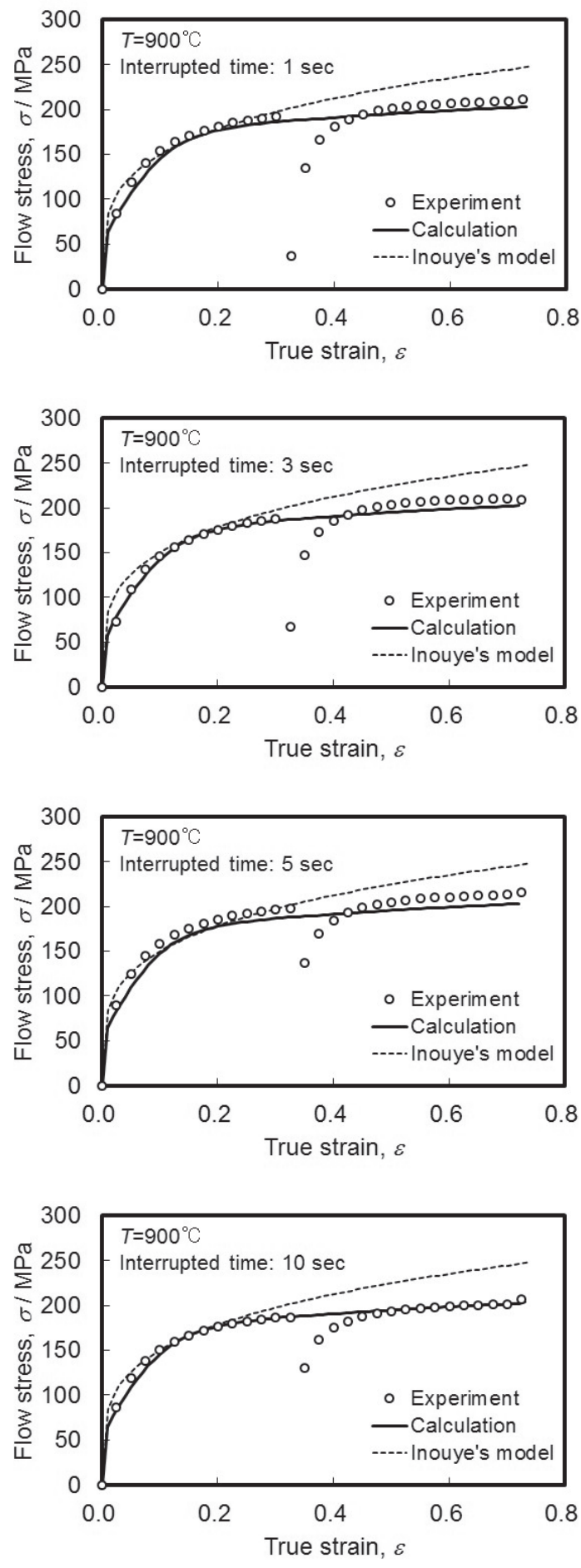

Fig. 9 Effect of deformation temperature on flow stress ratio for Steels A and D.

\subsection{Effect of dynamic recovery on prediction accuracy}

Figure 10 shows the stress-strain curves for a strain rate of $10 \mathrm{sec}^{-1}$ at deformation temperatures of 900, 1000 and $1100^{\circ} \mathrm{C}$ for Steels A and D. The plots are the experimental results and the lines represent the results of the flow stress calculations. The calculated lines showed good agreement with the experimental results at high total strains, even though the recovery tendencies of the materials were different. Next, to clarify the effect of dynamic recrystallization on prediction accuracy, Fig. 11 shows the stress-strain curves at strain rates from 0.1 to $10 \mathrm{sec}^{-1}$ at a deformation temperature of $1100^{\circ} \mathrm{C}$. From the results of the experiment with Steel A, a slight decrease in flow stress caused by dynamic recrystallization ${ }^{13)}$ occurred at a strain rate of $0.1 \mathrm{sec}^{-1}$. In this case, the calculated curve for the strain rate of $0.1 \mathrm{sec}^{-1}$ did not reflect the decrease in flow stress caused by dynamic recrystallization. On the other hand, in the case of Steel D, the calculated lines mostly show good agreement 

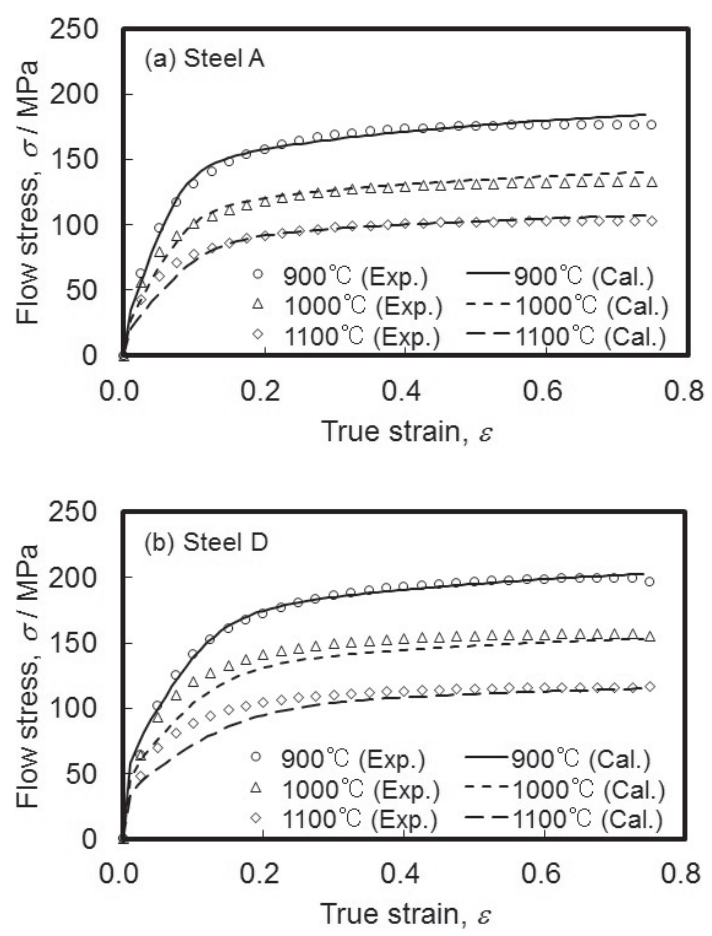

Fig. 10 Flow stress curves showing experimental and calculated results obtained at different temperatures for (a) Steel A and (b) Steel D.
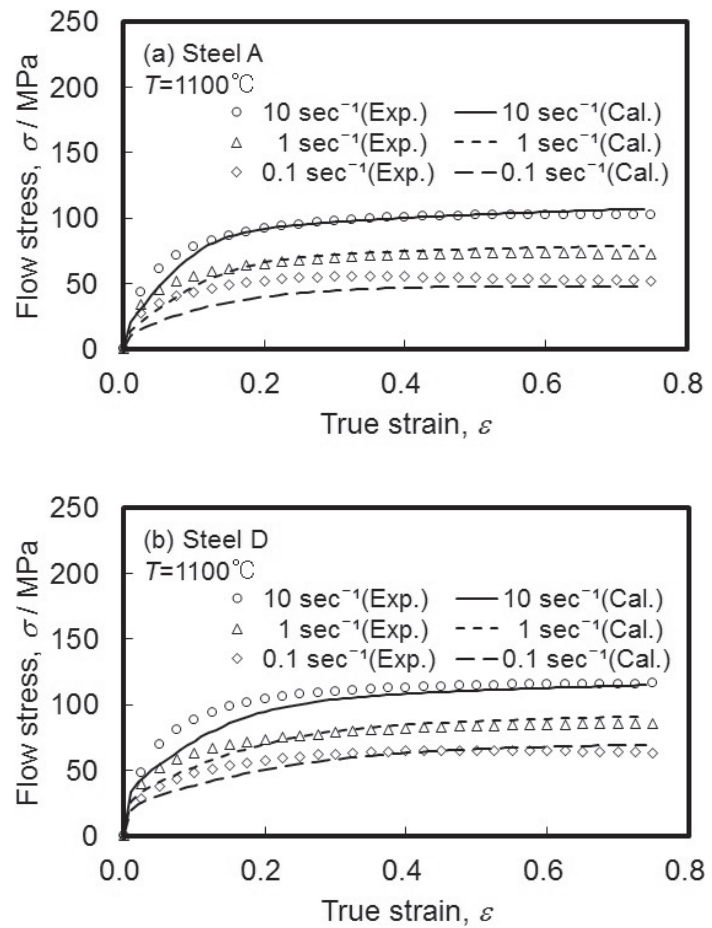

Fig. 11 Flow stress curves showing experimental and calculated results obtained at different strain rates for (a) Steel A and (b) Steel D.

with the experimental results up to a high total strain because dynamic recrystallization is inhibited, as can be seen from the experimental results. From these results, it is suggested that our proposed model enables prediction with good accuracy even when the deformation conditions, such as the strain rate, temperature and the chemical composition of the steel, are more complex, as long as dynamic recrystallization does not occur ${ }^{17)}$. This is because the effect of recovery considered in this model reflects not only static recovery but also dynamic recovery during deformation.

\section{Conclusions}

A mathematical model of flow stress for the hot processing of alloy steel was developed on the basis of Yoshino's model, and the effect of the chemical composition of steel on the prediction accuracy was investigated by performing multipass compressive tests. The following conclusions were obtained.

(1) The recovery characteristics of materials were reflected by the recovery coefficient $k$ in this model. The recovery coefficient is higher in materials in which recovery is strongly inhibited.

(2) Because the effect of recovery considered in this model reflects not only static recovery but also dynamic recovery during deformation, the proposed model enables prediction with high accuracy, even when the deformation conditions, such as the strain rate, temperature and the chemical composition of the steel, are more complex, unless static recrystallization occurs.

(3) This proposed model enables prediction with high accuracy even though the retardation of recovery varies with the material, provided static recrystallization does not occur. This is because the recovery characteristics of materials, such as the retardation of recovery during the time between passes due to the addition of alloying elements to the steel, are reflected well by the recovery coefficient $k$ in this model.

\section{REFERENCES}

1) K. Inouye: Trans. Iron Steel Inst. Jpn. 41 (1955) 506-515.

2) W. J. McG Tegart and A. Gittins: The Hot Deformation of Austenite, (J. B. Ballance Editor, American Institute of Mining and Petroleum Engineers, 1977) pp.1-46.

3) H.L. Andrade, M.G. Akben and J.J. Jonas: Metal. Trans. A. 14A (1967) 1967-1977.

4) Y. Saito, T. Enami and T. Tanaka: Trans. Iron Steel Inst. Jpn. 25 (1985) 1146-1155

5) S. Yamamoto, T. Sakiyama and C. Ouchi: Trans. Iron Steel Inst. Jpn. 27 (1987) 446-452.

6) T. Senuma, M. Suehiro and H. Yada: ISIJ Int. 32 (1992) 423-432.

7) A. Yoshie, T. Fujita, M. Fujioka, K. Okamoto and H. Morikawa: ISIJ Int. 36 (1996) 474-480.

8) M. Yoshino and T. Shirakashi: J. Jpn. Soc. Technol. Plast. 31 (1990) 1433-1438.

9) M. Yoshino and T. Shirakashi: J. Mater. Process. Technol. 48 (1995) 179-186.

10) T. Shirakashi and M. Yoshino: Strength Mater. 34 (2002) 223-227.

11) L.M. Clarebrough, M.E. Hargreaves and G.W. West: Proc. R. Soc. Lond. A Math. Phys. Sci. 232 (1955) 252-270.

12) K.P. Rao, Y.K.D.V. Prasad and E.B. Hawbolt: J. Mater. Process. Technol. 77 (1998) 166-174.

13) A. Laasraoui and J.J. Jonas: Metal. Trans. A. 22 (1991) 1545-1558.

14) R.P. Singh and R.D. Doherty: Metall. Trans., A, Phys. Metall. Mater. Sci. 23 (1992) 307-319.

15) S.F. Medina and J.E. Mancill: ISIJ Int. 36 (1996) 1070-1076.

16) M. Yoshino and T. Shirakashi: J. Jpn. Soc. Technol. Plast. 35 (1994) 1386-1393.

17) C. Ouchi and T. Okita: Trans. Iron Steel Inst. Jpn. 22 (1982) 543-551. 